\title{
Application of Sub-Critical Water Extraction in Pharmaceutical Industry
}

\author{
Xiaoxia Liang, Qiaojia Fan \\ Department of Pharmacy, College of Veterinary, Sichuan Agricultural University, Ya’an, Sichuan, China \\ Email: crystal_0406@126.com
}

Received June 2013

\begin{abstract}
Sub-critical water extraction is a brand-new separation technology. This paper mainly discussed the principle, advantages of sub-critical water extraction, and its applications ranging from the medicinal plants traditionally used in Europe and Asia to produce pharmaceutical extracts (such as volatile oil, tannins, flavonoids, anthraquinone, lactone, etc.). Meanwhile, the prospect of sub-critical water extraction in plant extractives is also explored. It will be widely used in the field of medical plants, bringing huge economic benefits, environmental benefits and social benefits.
\end{abstract}

Keywords: Sub-Critical Water Extraction; Pharmaceutical Extracts; Application

\section{Introduction}

At present, plant medicine, which mainly comes from plant extraction, has occupied nearly 30 percent to 40 percent among the thousands of worldwide used pharmaceutical products. As a natural healthy protection product, it has incomparable natural advantages, compared with the relative chemical drugs. Extraction and separation of effective pharmaceuticals, looking for leading compounds, is the first and most important step in the new drug development. However, chemical composition of various medicinal plants is very complex, usually containing many kinds of effective ingredients. Numerous methods, including conventional solvent extraction, steam distillation, and sublimation, etc., are known for extracting phytochemicals from plant materials, most based on sequential extraction processes incorporating one or more organic solvents in combination with washing steps. Phytochemical extracts produced by such methods must be further processed to remove all trace of the organic solvents, to remove impurities, and to separate and purify individual phytochemicals. While such methods are useful for extraction and purification of small quantities of phytochemicals for research purposes, they are difficult to scale to commercial through-put volumes because of the problems associated with cost-effectively, safely and completely removing and recovering the organic solvents from the extracts and spent plant materials. Furthermore, the types and concentrations of organic solvents must be carefully selected in order to avoid structural changes to the target phytochemicals during extraction that may adversely affect one or more of their desirable physical, chemical and biological properties.

In recent years, many new technologies and methods, such as ultrasonic extraction, microwave extraction, membrane separation technology, molecular distillation, macroporous resin adsorption and supercritical $\mathrm{CO}_{2}$ extraction technology, are introduced to the extraction and separation of effective components in medicinal plants, promoting the development of plant extracts industry. Among those new technologies, supercritical fluid extraction (referred to as SFE) [1,2], is the most compelling one, which is especially feasible for heat-sensitive material with its own unique advantages, including non-toxic, no solvent residue, high extraction rate, and free of environmental pollution. However, as every coin has two sides, SFE has less capacity, mainly for the extraction of high value-added products. Its application has been limited $[3,4]$, due to the high extraction pressure and equipment costs. Finally, with the development of SFE, a new extraction technique, "subcritical water extraction", emerged. Its principle, advantages, and applications of the extraction to a range of medicinal plants, traditionally used in Europe or Asia to produce pharmaceutical extracts (such as volatile oil, tannins, flavonoids, anthraquinone, lactone, etc.), will be introduced in this article.

\section{Principle of Sub-Critical Water Extraction}

Water, an inexpensive and environmentally friendly solvent is an ideal solvent for the industrial extraction of 
medical plants, but its use is limited due to poor extraction efficiency for most organic compounds such as polychlorinated biphenyls (PCBs), polycyclic aromatic hydrocarbons (PAHs) and most pesticides at ambient temperature. However, it has gained an increasing amount of attention due to its unique solvation properties, which can be altered by changing the temperature [5]. It is known that the physical and chemical properties of water within sealed systems can be manipulated by concurrently controlling the temperature and pressure, where by the water remains in a liquid state even though its temperature is significantly increased above its atmospheric boiling point of $100^{\circ} \mathrm{C}$. The polarity, viscosity, surface tension, and disassociation constant of sub-critical water are significantly lowered compared to water at ambient temperature and pressure conditions, thereby significantly altering its chemical properties to approximate those of organic solvents. Consequently, pressurized lowpolarity water under sub-critical conditions can easily solubilize organic compounds from polar (at lower temperatures) to nonpolar (at higher temperatures), such as phytochemicals which are normally insoluble in ambient water [6]. In this condition, it is known as "sub-critical" or "hot/liquid" water. Sub-critical water can be maintained in the liquid form until a temperature of $374^{\circ} \mathrm{C}$ and a pressure of 221 bars are reached after which, it becomes supercritical water [7,8]. Sub-critical Water Extraction (SBWE), also known as hot water extraction, pressurized (hot) water extraction, pressurized low polarity water extraction, high-temperature water extraction, superheated water extraction or hot liquid water extraction, is such a promising "green" technique based on the use of water at a sub-critical state as the sole extraction solvent $[6,9]$. A further advantage of sub-critical water extraction is that the high temperature and pressure produce high diffusion rates which promote very efficient extraction of the raw material. In addition, that rates vary according to different chemical structures $[10,11]$ of organic compounds. Therefore, extraction with subcritical water can be both selective and rapid.

\section{Advantages of Sub-Critical Water Extraction}

As we mentioned above, from water-solubility to liposoluble substances were successively extracted with SBW. Its ability to dissolve nonpolar organics is similar to that of organic solvents, which are expensive, potentially harmful to the operator, and need to be disposed of. Using SBWE instead is highly desirable from environmental and health perspectives. It shows lower handling time and solvent consumption, reducing the loss of heatsensitive compounds, and totally eliminates the use of toxic organic solvent, with no organic solvent remain, with no waste produced at the same extraction efficiency. The technique could achieve selectively extraction of polar, moderately polar, and nonpolar organics by altering extraction parameter, such as temperature, pressure and co-solvent. Meanwhile, compared with supercritical extraction (SFE) $\left(\mathrm{CO}_{2}\right.$ used particularly), SBW can be used in the extraction of substances from moderately polar to heavy molecular weight in medical plants. This just compensates for the drawback of SFE $\left(\mathrm{CO}_{2}\right.$ used particularly, which can just extract nonpolar or light molecular weight substance and will not extract the compounds most readily soluble in methanol or aqueous ethanol, including the important classes of flavonoids, lignans and other related polyphenolic compounds.) Recently, SBEW has been applied largely abroad. Most of these reports focused on the determination of organic pollutants [12-14] in soils, sludges and sediments, and the extraction of spice components from plants. Its application in the field of pharmaceutical industry is also encouraging [15].

\section{Application in Pharmaceutical Industry}

Sub-critical water extraction has been extracted the most active compounds from herbs, such as Rosmarinus officinalis (rosemary), Matricaria recutita (German chamomile), Cassia angustifolia (senna), Valeriana officinalis (valerian), Scutellaria baicalensis (Baikal skullcap), Schisandra chinensis (Wuweizu), Zingiber officinale (ginger), Astragalus Membranaceus, etc. [16]. Those extracts were demonstrated to exhibit a composition essentially similar to that of the corresponding methanol or aqueous alcohol, which would show comparable pharmacological activities.

\subsection{Extraction of Volatile Oils}

Volatile oil, also known as essential oil, is present in a class of plants with aromatic smell, which is water insoluble and can be distilled with steam. As an important class of active ingredients, essential oils are volatile oillike components of the general, with a variety of pharmacological activities and applications in medicine and food industry. Traditional methods include steam distillation and organic solvent extract, indicating much more shortcomings, such as volatile components loss, low extraction efficiency, heating for a long time, organic solvent residual and so on. In 1998, Basile et al [17] first confirmed that the sub-critical water extraction was a practical method for the essential oil. In their research, the extracts from rosemary was compared with that from steam distillation, the former showed pleasantly surprised advantages, including short extraction time, high yield of oxygenated compounds, good quality and lower energy consumption. From that brand-new start, sub-critical 
water extraction has been applied on essential oils of different kinds of herbs, including Fructus Foeniculi [18], Thymbra spicata [19], Marjoram [20], Peppermint [21,22], Laural [23], Eucalyptus [24], and clove buds [25], etc., which were compared with hydro-distillation, supercritical carbon dioxide and extraction. The effects of experimental parameters (extraction temperature, extraction pressure, time and entrainer on essential oil) were also analyzed. All of the further evidences supported the sub-critical water extraction as a powerful alternative of the extraction of essential oil from herbs with higher oil yield and shorter extraction time.

\subsection{Extraction of Plant Phenols}

As a kind of widespread active ingredients of many medicinal plants in nature, plant phenolic compounds mainly exist in plants, roots, leaves the skin, shell and pulp, including tannins, flavonoids, anthraquinones, lignin and some simple phenols. In recent years, as the research $[26,27]$ showed that some polyphenols could inhibit tumor development in animals and humans, prevent cardiovascular disease, as well as anti-mutation, anti-virus and anti-oxidation, the study of polyphenols has been attracted more and more attention. Sub-critical water has been proved good to extract plant phenolic compounds according to many results of researches. Some examples will be given below.

\subsubsection{Extraction of Tannins}

G. M. Matilde [28] extracted grape seed extract in batch and continuous Manners at different temperatures $\left(50^{\circ} \mathrm{C}\right.$, $100^{\circ} \mathrm{C}, 150^{\circ} \mathrm{C}$ ), the result showed that a continuous extraction of material is conducive to the dissolution of tannin. In the research of Antuon [29], when the extraction time fixed to $20 \mathrm{~min}$, the total polyphenol content of grape seed by sub-critical water extraction is 2 times higher than that of $70 \%$ ethanol extraction.

\subsubsection{Extraction of Flavonodis}

Flavonoids are a subgroup of plant polyphenols, widely found in fruits, vegetables, beans, tea and many medical plants. As a type of phytochemicals, they have been extensively applied to treat and inhabit disease and medically functional disorders as healers, antimicrobial agents, as well as antioxidants. However, the poor water solubility and lipid solubility limit their application. With the rise of sub-critical water extraction, a study, focused on the influence of different pressures, temperatures and flow rates in the water extraction of five isoflavones from defatted soybeans, was started by Chang et al [30]. The results exhibited the best extraction yield of total isoflavones up to $99.7 \%$. Then Charlotta Turner et al. [31] demonstrated that sub-critical water extraction following by $\beta$-glucosidase-catalyzed hydrolysis was a rapid me- thod to determine the content of quercetin and isorhamnetin in onion samples, and environmentally sustainable as the only use of water. In another research, Zhi-hong $\mathrm{Xu}$ et al. [32] has figured out the influence of temperature, pressure, time, particle size, solvent ratio on the extraction of baicalin from Scutellariae Radix by sub-critical water and compared with the organic solvent extraction method. The result turned out that while maintaining the same extraction effect, the former had greatly reduced the extraction time and avoided the organic solvent pollution. Furthermore, flavonoids were extracted by subcritical water from Oregano leaves [33].

\subsubsection{Extraction of Anthraquinones}

As another subtype of plant polyphenols, anthraquinones present various biologically activities, which make the potential usefulness in several medical applications. A study [34] of the extraction anthraquinones from dried roots of Morinda citrifolia (Noni)., which possesses several therapeutic properties, such as antiviral, antibacterial, and anticancer, determined their solubility in sub-critical water and indicated the increase of extraction yield with the rise of temperature, while almost unaffected by pressure. In the extraction of damnacanthal, which is the most valuable anthraquinone compound in the roots of Morinda citrifolia (Noni)., Anekpankul et al [35] investigated the extraction yield at different temperatures and flow rates, and suggested that the sub-critical water extraction would be a promising method. In addition, the extraction of anthraquinones by sub-critical water from the roots of mulberry was also reported [36-38].

\subsubsection{Extraction of Lignins and Others}

Researches on the sub-critical water extraction in other subtypes of nutraceutical phenolic compounds, such as lignins [39,40], phenolic acids [41-46], and some simple phenols [47], were reported, besides the examination of parameters affecting extraction. For example, in the study of the water extraction of polyphenol compounds in bitter melon, Budrat [41] reported that as the extraction temperature increased, the total polyphenol content could increase, while the extracts at lower temperature showed higher antioxidant activity. Furthermore, their antioxidant activity was about three times higher than methanol extraction or ultrasonic extraction in boiling water.

\subsection{Extraction of Lactones}

Kavalactones, active ingredients from the roots and rhizomes of piper methysticum forst, are widely used as medicine and soft drink in Europe and America. Kubatova et al. [48] compared its sub-critical water extraction with that of soxhlet extraction, ultrasonic extraction in boiling water and acetone extraction. The result turned out that the extraction rate of the first method, sub-criti- 
cal water extraction, was much higher than the others, whether the peper was crushed or not.

\subsection{Extraction of Others}

Baek et al [49] examined the influence of different temperatures and time on the sub-critical water extraction yield of antioxidant nutrients from Glycyrrhiza. The result showed that the antioxidant activity and nutrient content of the extract by sub-critical water has been enhanced, and significantly affected by the temperature and time. Besides, in a further research, Isabella D'Antuono [29] have confirmed the feasibility and advantages of sub-critical water as available extraction solvent for the recovery of natural antioxidants from by-products of the food industry.

\section{Conclusion}

In conclusion, the use of sub-critical water as available alternative solvent for the extraction of phytochemicals from medical plants has been shown to be feasible. In particular, the process, not involving any use of organic solvents, does not originate pollution problems, associated either with the desolventization step of the extracts, or to inevitable losses of the organic solvent during the process. Hence, as the improved living standards and social progress, the use of sub-critical water could represent a way for realizing a true green process. Currently, sub-critical water extraction technology has been applied to the essential oil, tannins, flavonoids, lactones, anthraquinone, glycosides, lignans, protein, pectin, polysaccharides and organic acids. However, due to the complexity and similarity of plant active ingredients, sub-critical water extraction technique alone often can not meet the requirements of purity, its development, coupled with other separation means, such as sub-critical water extraction-Membrane Separation and Purification, sub-critical water extraction-Molecular distillation, sub-critical water extraction-Large Macroporous resin adsorption, etc., is of great significance. Further studies are being carried out in order to investigate more deeply the composition of the pharmaceutical extracts and sub-critical water extraction in the field of medical plants will be widely used, bringing huge economic benefits, environmental benefits and Social benefits.

\section{REFERENCES}

[1] N. N Datta, A. P. Baruah and P. Phukan, "Supercritical Extraction in the Pharmaceutical Industry," Chemical Engineering World, Vol. 26, No. 2-3, 1991, pp. 25-29.

[2] I. D. Wilson, et al., "Supercritical Fluid Chromatography and Extraction of Pharmaceuticals," Applications of Supercritical Fluids in Industrial Analysis, 1993, pp. 74103.
[3] C. L. Phelps, N. G. Smart and C. M. Wai, Journal of Chemical Education, Vol. 73, No. 12, 1996, pp. 11631168.

[4] J. C. Zhang, "Supercritical Fluid Extraction," Chemical Industry Press, Beijing, 2001, pp. 105-144.

[5] S. Rovio, K. Hartonen, Y. Holm, R. Hiltunen and M. L Riekkola, "Extraction of Clove Using Pressurized Hot Water," Flavour and Fragrance Journal, Vol. 14, 1999, pp. 399-404.

http://dx.doi.org/10.1002/(SICI)1099-1026(199911/12)14 :6<399::AID-FFJ851>3.0.CO;2-A

[6] L. Ramos, E. M. Kristenson and U. A. T. Brinkman, "Current Use of Pressurised Liquid Extraction and Subcritical Water Extraction in Environmental Analysis," Journal of Chromatography A, Vol. 975, 2002, pp. 3-29. http://dx.doi.org/10.1016/S0021-9673(02)01336-5

[7] A. A. Clifford, "Changes of Water Properties with Temperature,” 2008. http://www.criticalprocesses.com/Use\%20of\%20enthalpi es\%20to\%20calculate\%20energy\%20needed.htm

[8] M. Chaplin, "Explanation of the Physical Anomalies of Water,” London South Bank University, 2008. http://www.lsbu.ac.uk/water/explan5.html

[9] R. M. Smith, "Extractions with Superheated Water," Journal of Chromatography A, Vol. 975, 2002, pp. 31-46. http://dx.doi.org/10.1016/S0021-9673(02)01225-6

[10] A. Basile, et al., "Extraction of Rosemary by Superheated Water," Journal of Agricultural and Food Chemistry (American Chemical Society), Vol. 46, No. 12, 1998, pp. 5205-5209.

[11] M. H. Eikani, F. Golmohammad and S. Rowshanzamir, "Subcritical Water Extraction of Essential Oils from Coriander Seeds (Corianrum sativum L.),” 2008. http://www.aseanfood.info/Articles/11017821.pdf

[12] D. J. Miller, S. B. Hawthorne, A. M. Gizir and A. A. Clifford, "Solubility of Polycyclic Aromatic Hydrocarbons in Subcritical Water from 298 K to 498 K," Journal of Chemical Engineering Data (American Chemical Society), Vol. 43, No. 6, 1998, pp. 1043-1047.

[13] S. Kipp, et al., "Coupling Superheated Water Extraction with Enzyme Immunoassay for an Efficient and Fast PAH Screening in Soil,” Talanta (Elsevier Science BV), Vol. 46, No. 3, 1998, 385-393.

[14] K. Hartonen, Kronholm and Reikkola, "Sustainable Use of Renewable Natural Resources Principles and Practice. Chapter 5.2, Utilisation of High Temperature Water in the Purification of Water and Soil,” University of Helsinki Department of Forest Ecology, 2005. http://www.mm.helsinki.fi/mmeko/tutkimus/SUNARE/pd f/52_Hartonen_etal.pdf

[15] M. D. Luque de Castro, M. M. Jim Enez-Carmona and V. Fernandez-Perez, "Towards More Rational Techniques for the Isolation of Valuable Essential Oils from Plants," Trends in Analytical Chemistry, Vol. 18, 1999, pp. 708716. http://dx.doi.org/10.1016/S0165-9936(99)00177-6

[16] W. G. William and D. Kenneth, "Sub-Critical Water Extraction of Medicinal Plants,” WO/2010/034971, PCT/ GB2009/002229. 
[17] A. Basilea, M. M. Jimenez-Carmona and A. A. Clifford, "Extraction of Rosemary by Superheated Water," Journal of Agricultural and Food Chemistry, Vol. 46, No. 12, 1998, pp. 5205-5209.

[18] G. Gmiz and M. D. Luque de Castro, "Continuous SubCritical Water Extraction of Medicinal Plant Essential Oil Comparison with Conventional Techniques,” Talanta, Vol. 51, 2000, pp. 1179-1185. http://dx.doi.org/10.1016/S0039-9140(00)00294-0

[19] M. Z. Ozel, F. Gogus and A. C. Lewis, "Sub-Critical Water Extraction of Essential Oil from Thymbra Spicata," Food Chemistry, Vol. 82, No. 3, 2003, pp. 381-386.

[20] M. M. Jimnez Carmona, J. L. Ubera, M. D. Luque de Castro, et al., "Comparison of Continuous Sub-Critical Water Extraction and Hydro-Distillation of Marjoram Essential Oil,” Journal of Chromatography A, Vol. 855, 1999, pp. 625-632. http://dx.doi.org/10.1016/S0021-9673(99)00703-7

[21] A. Kubatova, A. J. M. Lagadec, D. J. Miler, et al., "Selective Extraction of Oxygenates from Savory and Peppermint Using Sub-Critical Water," Flavour and Fragrance Journal, Vol. 16, No. 1, 2001, pp. 64-73.

[22] A. Ammann, D. C. Hinz, R. S. Addleman, et al., "Superheated Water Extraction, Steam Distillation and SFE of Peppermint Oil," Fresenius Journal of Analytical Chemistry, Vol. 364, No. 7, 1999, pp. 650-653.

[23] Z. V. Fernandez Pere, M. M. Jimenez Carmona, M. D. Leque de Castro, "An Approach to the Static-Dynamic Sub-Critical Water Extraction of Laurel Essential Oil Comparison with Conventional Techniques,” Analyst, Vol. 125, 2000, pp. 481-485. http://dx.doi.org/10.1039/a907244f

[24] M. M. Jimenez Carmona and M. D. Luque de Castro, "Isolation of Eucalyptus Essential Oil for GC-MS Analysis by Extraction with Sub-Critical Water," Chromatographia, Vol. 50, 1999, pp. 578-582. http://dx.doi.org/10.1007/s002160051400

[25] A. A. Clifford, A. Basile and R. Ai-Saidish, “A Comparison of the Extraction of Clove Buds with Supercritical Carbon Dioxide and Superheated Water," Fresenius Journal Analysis Chemistry, Vol. 364, 1999, pp. 635-637. http://dx.doi.org/10.1007/s002160051400

[26] S. Bi and D. Yin, "Plant Polyphenol," Science Press, Beijing, 2000, pp. 1-46.

[27] D. W. Sun, "Plant Tannic Chemistry,” China Forest Press, Beijing, 1992, pp. 1-10.

[28] M. G. Marino, et al., Analytica Chimica Acta, Vol. 563, 2006, pp. 44-50.

http://dx.doi.org/10.1016/j.aca.2005.10.054

[29] I. D. Antuon, "Use of Sub-Critical Water for the Extraction of Natural Antioxidants from By-Products and Wastes of the Food Industry," 14th Workshop on the Developments in the Italian PhD Research on Food Science Technology and Biotechnology, University of Sassari Oristano, 2009, pp. 16-18.

[30] L. H. Chang, Y. C. Cheng and C. M. Chang, "Extracting and Purifying Isoflavones from Defatted Soybean Flakes Using Superheated Water at Elevated Pressures,” Food
Chemistry, Vol. 84, 2004, pp. 279-285.

http://dx.doi.org/10.1016/S0308-8146(03)00212-7

[31] C. Turner, P. Turner, G. Jacobson, K. Almgren, M. Waldebäck, P. Sjöberg, E. N. Karlssonb and K. E. Markides, "Sub-Critical Water Extraction and $b$-Glucosidase-Catalyzed Hydrolysis of Quercetin Glycosides in Onion Waste,” Green Chemistry, Vol. 8, 2006, pp. 949-959. http://dx.doi.org/10.1039/b608011a

[32] Z. H. Xu, G. S. Qian, S. K. Liu, Z. W. Li and X. Y. Chen, "Study on Subcritical Water Extraction of Baicalin from Radix Scutellariae Coupled to High Performance Liquid Chromatographic Analysis," Chinese Journal of Chromatography, Vol. 22, No. 1, 2004, pp. 44-47.

[33] I. Rodriguez Meizoso, et al., Chem Functional Characterization, Vol. 41, 2006, pp. 1560-1565.

[34] A. Shotipruk, J. Kiatsongserm, P. Pavasant, M. Goto and M. Sasaki, "Pressurized Hot Water Extraction of Anthraquinones from the Roots of Morinda citrifolia," Biotechnology Progress, Vol. 20, 2004, pp. 1872-1875. http://dx.doi.org/10.1021/bp049779x

[35] T. Anekpankul, M. Goto, I. M. Sasak, et al., "Extraction of Anticancer Damnacanthal from Roots of Morinda citrifolia by Sub-Critical Water," Separation and Purification Technology, Vol. 55, 2007, pp. 343-349. http://dx.doi.org/10.1016/j.seppur.2007.01.004

[36] B. P. Ravane, et al., Journal of Supercritical Fluids, Vol. 37, 2006, pp. 390-396. http://dx.doi.org/10.1016/j.supflu.2005.12.013

[37] A. Shotipruk, et al., Biotechnology Progress, Vol. 20, 2004, pp. 1872-1875. http://dx.doi.org/10.1021/bp049779x

[38] T. Anekpankul, et al., Separation and Purification Technology, Vol. 55, 2007, pp. 343-349. http://dx.doi.org/10.1016/j.seppur.2007.01.004

[39] J. E. Cacace and G. Mazza, Journal of Food Engineering, Vol. 77, 2006, pp. 1087-1095. http://dx.doi.org/10.1016/j.jfoodeng.2005.08.039

[40] J. W. Kim and G. Mazza, Journal of Agricultural and Food Chemistry, Vol. 54, 2006, pp. 7575-7584. http://dx.doi.org/10.1016/j.seppur.2008.11.014

[41] P. Budrat and A. Shot Ipruk, "Enhanced Recovery of Phenolic Compounds from Bitter Melon (Momordica charantia) by Subcritical Water Extraction,” Separation and Purification Technology, Vol. 66, No. 1, 2009, pp. 125-129.

[42] P. Budrat and A. Shotipruk, Separation and Purification Technology, Vol. 66, 2009, pp. 125-129. http://dx.doi.org/10.1016/j.seppur.2008.11.014

[43] W. J. Kim, et al., Journal of Supercritical Fluids, Vol. 48, 2009, pp. 211-216. http://dx.doi.org/10.1016/j.supflu.2008.11.007

[44] I. Aditya Kulkarn, et al., Journal of Wood Science, Vol. 54, 2008, pp. 153-157. http://dx.doi.org/10.1007/s10086-007-0916-6

[45] A. Shamash, et al., Journal of Food Process Engineering, Vol. 31, 2008, pp. 330-338. http://dx.doi.org/10.1111/j.1745-4530.2007.00156.x 
[46] J. Y. Baek, et al., Separation and Purification Technology, Vol. 63, 2008, pp. 661-664.

http://dx.doi.org/10.1016/j.seppur.2008.07.005

[47] P. Rangsriwong, N. Rangkadilok and A. Shotipruk, "SubCritical Water Extraction of Polyphenolic Compounds from Terminalia chebula Fruits," Chiang Mai Journal of Science, Vol. 35, No. 1, 2008, pp. 103-108.

[48] A. Kubatova, D. J. Miller and S. B. Hawthorne, "Sub-
Critical Water and Organic Solvents for Extracting Kava Lactones from Kava Root,” Journal of Chromatography A, Vol. 923, No. 1, 2001, pp. 187-194.

[49] J. Y. Baek, J. M. Lee and S. C. Lee, "Extract Ion of Nutraceutical Compounds from Licorice Roots with SubCritical Water," Separation and Purification Technology, Vol. 63, 2008, pp. 661-664.

http://dx.doi.org/10.1016/j.seppur.2008.07.005 